\title{
EDITORIAL
}

\section{The Future of Medical Care for Older Adults in Canada}

DOI:http://dx.doi.org/10.5770/cgj.17.181

We are excited to present a linked pair of articles about the future of medical care for older adults. Dr. Andrew and Dr. Rockwood present a commentary on the recent report written by Dr. David Oliver with his colleagues from the King's Fund, entitled "Making Health and Care Systems Fit for an Ageing Population." This report emphasizes the need for less use of acute care as the mechanism deliver care to older adults, and recognition that the 'single disease' model of illness rarely works in this vulnerable population. This commentary is accompanied by a response written by Dr. Oliver, who attempts to translate some of his report's recommendations into a Canadian context.

We also are pleased to publish some original research articles that directly relate to older adults' interactions with the acute care system. Dr. Lantham et al. have examined emergency room utilization patterns in an acute emergency room context. In addition, Dr. Diachun investigates the utility of the internal medicine clerkship as an educational platform for educating medical students about geriatric medicine issues.
Dr. Rapoport (one of our associate editors) has written an excellent editorial providing a geriatric psychiatrist's top five concerns about the impact of the new DSM-5 guidelines. Additionally, we also have provided all of the abstracts for the research presented at our annual Canadian Geriatrics Society Scientific Sessions and the abstracts presented at the Canadian Coalition for Seniors' Mental Health (CCSMH) and Canadian Academy of Geriatric Psychiatry‘s (CAGP) Joint Scientific Meeting.

We hope you enjoy our last issue for 2014! Dr. Maxwell, Dr. Rapoport and I would like to thank the membership of the Canadian Geriatrics Society for allowing us to provide a platform to continue to disseminate Canadian geriatric and gerontological research.

See you next year!

Dr. Kenneth M. Madden Editor-in-Chief Canadian Geriatrics Journal 